\title{
Tenebrio molitor L., entomophagy and processing into ready to use therapeutic ingredients: a review
}

\begin{abstract}
The consumption of insects is known as entomophagy. Edible insects have been consumed for a long time in the traditional diets of many non-Western countries, but in recent times, the Food and Agriculture Organization of the United Nations (FAO) recognize them as having a high potential to treat malnutrition and food shortages without requiring large amounts of land or infrastructure. The larvae of Tenebrio Molitor L., the mealworm, have been processed to be as high in protein content as fish and meat. They are also fairly high in fatty acids, especially polyunsaturated omega-3 and 6, comparable with the content of fish and higher than in beef and pork. They possess a variety of vitamins and minerals such as: magnesium, copper, iron, manganese, phosphorus, selenium and zinc as well as, riboflavin, pantothenic acid and biotin. These qualities would make them a possible food ingredient in the US (based on current novelty trends) if US consumers would acknowledge and learn to accept insect-based products. In areas where insects are a traditional part of the diet, processed mealworms can be used as a successful ingredient in emergency relief meals.
\end{abstract}

Keywords: mealworm, tenebrio molitor, proximate analysis, meal relief
Volume 8 Issue 3 - 2018

\section{Sofia Feng}

Department of Food, Bioprocessing and Nutritional Sciences, NC State University, USA

\section{Correspondence: Sofia Feng, Department of Food,} Bioprocessing and Nutritional Sciences, NC State University, 400 Dan Allen Dr. Raleigh, NC, 27695, USA, Tel + I (919)-4541494, Email sfeng4@ncsu.edu

Received: June 14, 2018 | Published: June 22, 2018
Abbreviations: FAO, food and agriculture organization; MUFAs, monounsaturated fatty acids; PUFAs, polyunsaturated fatty acids; CVD, cardiovascular disease; MAM, moderately acute malnutrition; NRV, nutrient reference value; FDA, food and drug administration; WFP, world food program; WHZ, weight for height z-score

\section{History}

Humans have consumed insects for thousands of years. Durst ${ }^{1}$ made reference to insect consumption before Christian times by Europeans and its consumption has also been described in the Bible. They have been generally consumed in very poor countries ${ }^{2}$ or reared as feed for reptile, fish and avian pets in developed countries. ${ }^{3}$ Historically, insects have been eaten in Africa, Asia and Latin America ${ }^{4}$ Currently, there are more than 2,000 insect species consumed in 113 countries all over the world. ${ }^{5}$ The consumption of whole insects and insect-containing foods historically have had low acceptance in countries in the Western world. In view of the increasing world population demands for protein with low environmental impacts, proteins extracted from insects can have diverse applications and might potentially have greater success for acceptance as an ingredient for human foods. ${ }^{4,6}$

The concept of "mini-livestock" or insect farming is a low-tech activity and requires low-capital investment. Conventional forms of farming insects for food and feed include rearing honey bees, producing silk from silkworms and scaling insects such as cochineal from which carmine dye is derived. Carmine dye is a red colorant widely used in the food industry. ${ }^{3}$ At present insects is not part of the Western diet. It has been speculated that there are several reasons for this. For example, insects were not included in the plant and animal domestication pattern. Historically, only large animals (and plants) were domesticated particularly by Europeans conquering the new world. Domestication allowed them the advantage of the control on food production, which is evidenced by their worldwide conquests. van Huis and collaborators ${ }^{1,3}$ suggest that without European colonization and imports the domestication of edible insects would have been more advanced and widespread for multiple species.

Insects also do not reproduce well during low temperature season, which results in long insect-less winters. Also insects present the difficulty of being collected. Ease of access and the total quantity accumulation for the task seems a complication for insects as human food. ${ }^{1}$

\section{Tenebrio molitor $\mathbf{L}$.}

Among edible insects the larva or yellow worm of Tenebrio Molitor Linnaeus (T. molitor), 1758 (Coleoptera, Tenebrionidae) is notable. It is approximately, $2.5-3.5 \mathrm{~cm}$ in length with a weight of approximately $0.2 \mathrm{~g} .{ }^{2,4} \mathrm{As}$ an edible insect it is currently harvested and consumed in countries in Africa, Asia and Australia. ${ }^{4}$ In the literature of the reported cases of uncontrolled post-harvest pests, T. molitor is among the largest beetles that can infest food products in warehouses, mainly in cereal and other grain warehouses, causing approximately $50 \%$ loss of production when infested. ${ }^{2-4}$

\section{Meal worm growth, rearing and processing}

Typically, the life cycle of $T$. molitor can be described as the following: the beetles begin to lay eggs after 4 to 17days after copulation. A single female beetle can generate an average of 500 eggs. The embryonic development lasts from 4 to 6 days, which can be accelerated with a slight increase in temperature $\left(25\right.$ to $\left.27^{\circ} \mathrm{C}\right)$. Larval period is about 3 months. At this stage, the insect can be harvested, processed and consumed. Larvae not harvested after this phase will turn into a pupa, a stage that lasts 5 to 6days and culminates in an adult individual. ${ }^{4}$ Because of this life cycle, T. molitor is a holometabolous. Holometabolous insects undergo a true metamorphosis from egg to larva to pupa to adult. Hemimetabolous insects undergo an incomplete metamorphosis from egg to nymph to adult. ${ }^{5}$ Insects undergo a metamorphosis with different development stages. In the study, yellow mealworms developed in 12 to 32 weeks. $^{7}$ 


\section{Chemical composition}

A summary of the nutritional components found in dried mealworms can be found in Table 1. Mealworms are considered a nutritionally dense form of energy, rich in protein, fats, micronutrients and dietary fiber. ${ }^{2,5}$ According to Zhao et al., ${ }^{6}$ mealworms are composed on the average of $15 \%$ fat and $20 \%$ protein. Nowak et al., ${ }^{8}$ reported $214 \pm 39$ Kcal for $100 \mathrm{~g}$; protein values in larvae from 13.68 to $22.32 \mathrm{~g} / 100 \mathrm{~g}$.

Table I Nutritive value in $100 \mathrm{~g}$ of mealworms, fresh weight

\begin{tabular}{|c|c|c|c|}
\hline Proximate & $\begin{array}{l}\text { Nowak, } \\
2016\end{array}$ & $\begin{array}{l}\text { Payne et al. } \\
2016\end{array}$ & $\begin{array}{l}\text { (Different } \\
\text { authors) }\end{array}$ \\
\hline Moisture (g/l00g) & $62 \pm 4.6$ & Not available & $50^{6}$ \\
\hline $\begin{array}{l}\text { Energy } \\
\text { (Kcal/lo0g) }\end{array}$ & 214 & 247 & $213^{6}$ \\
\hline $\begin{array}{l}\text { Total Protein } \\
(\mathrm{g} / \mathrm{l00g})\end{array}$ & 13.68-22.32 & 19.4 & $\begin{array}{l}\text { I } 4 \text { to } 25 \text { van } \\
\text { Huis et al. }{ }^{3}\end{array}$ \\
\hline Total Fat (g/l00g) & $13.07 \pm 3.88$ & 12.3 & $13^{6}$ \\
\hline $\begin{array}{l}\text { Carboydrate } \\
(g / 100 g)\end{array}$ & 3.61 & Not available & $\begin{array}{l}\text { 3van Huis et } \\
\text { al. }^{3}\end{array}$ \\
\hline $\begin{array}{l}\text { Total Dietary } \\
\text { Fiber (g/l00g) }\end{array}$ & $2.38 \pm 0.21$ & Not available & $\begin{array}{l}2 \text { van Huis } \\
\text { et al. }{ }^{3}\end{array}$ \\
\hline
\end{tabular}

\section{Lipid}

Lipids are macronutrients compounds that are generally soluble in organic solvents and are the major components in adipose tissue, formed by long chains of carbon and hydrogen atoms. ${ }^{9}$ Compared with 4 $\mathrm{kcal} / \mathrm{g}$ from the breakdown of carbohydrates and proteins, the complete oxidation of fatty acids provides a high caloric content of $9 \mathrm{kcal} / \mathrm{g} .{ }^{10}$ The term lipid encompasses molecules such as sterols, glycerols, fatty acids (including tri-, di-, monoglycerides, phospholipids) and others. Sterol lipids, such as cholesterol and its derivatives, are an important component of membrane lipids; however, because of their function as energy storage, triglycerides are the lipids that comprise the bulk of storage fat in plant and animal tissues. They can either be solid or liquid at room temperature (Fennema, 1996). Dietary lipids are important in nutrition. They supply calories, essential fatty acids, increase palatability of foods and serve as vitamin carriers. Animal fats are typically solid at room temperature and consist of saturated fats, which are characterized by only carbon-to-carbon single bonds. This characteristic allows them to have a relatively high melting point. ${ }^{9}$ Plant oils, however, are derived from seeds and tropical trees, liquid at room temperature with a narrow melting range given by their nature of unsaturated fats, which are characterized by the presence of double bonds along the chain of fatty acids. ${ }^{9}$ Phospholipids are lipids containing phosphoric acid as part of their structure where either one or two hydrocarbon chains are derived. Given by this structure, all phospholipids contain a polar head and one or two hydrocarbon chains. ${ }^{9}$

Fat values for larvae show an ample range from 8.90 to $19.94 \mathrm{~g} / 100 \mathrm{~g} ;{ }^{8}$ however, Zhao et al., ${ }^{6}$ reports $33 \%$ for fat analyzed with continuous organic extraction. Such great variability is explained by Nowak et al., ${ }^{8}$ that points out the variability could be given by differences in average weight, age or size and different diets being fed to mealworms. Mealworms contain a large proportion of longer unsaturated long fatty acid chains, particularly of oleic acid (18:1) and linoleic acid (18:2 or $n-6){ }^{2,7}$ Aguilar-Miranda ${ }^{2}$ also reported a small but significant amount of linolenic (C18:3 n-3) found in T. molitor. Monounsaturated fatty acids (MUFAs) and polyunsaturated fatty acids (PUFAs) are considered healthy fats and have been proven to aid in lipid lowering and prevention of cardiovascular disease (CVD). ${ }^{10} \mathrm{~T}$. molitor provides considerable amounts of PUFA $(3.17-6.75 \mathrm{~g} / 100 \mathrm{~g}$ in fresh weight basis) representing between $21 \%$ and $62 \%$ of total lipids. Rumpold \& Schlüter ${ }^{5}$ in their review reported a mean PUFA content of $27 \%$ of total lipid for the insect order Coleoptera, which lies within the range of findings; however, the range within this group was very wide (2.78-65.29\% PUFA of total lipids). ${ }^{8}$ Polyunsaturated and monounsaturated fatty acids oxidize more readily than saturated fatty acids releasing unpleasant odors and off flavors. This phenomenon is known as rancidity. ${ }^{9}$ European Food Safety Authority (EFSA) mentions special consideration when processing insect food products because of the high amounts of unsaturated fatty acids present that give rise to rapid oxidation, causing foods to go rancid quickly. ${ }^{11}$ According to van Huis et al., ${ }^{3}$ polyunsaturated fatty acids in mealworm composition are mostly found in the phospholipids.

\section{Protein}

Proteins are essential in biological systems. Amino acids are the basic structural units that can be conformed in primary, secondary, tertiary or quaternary structures. Of the 20 amino acids, 9 are considered essential because they cannot be synthesized by humans. These are: phenylalanine, valine, threonine, tryptophan, isoleucine, methionine, leucine, lysine and histidine (The National Academics of Science, Engineering, Medicine [NAP].${ }^{12}$ Basic units align in highly complex polymers with a multitude of three-dimensional structural forms that give proteins different functionality. ${ }^{9}$ Examples of proteins include: enzymes that are catalyzers in biochemical processes, structural proteins such as collagen, keratin and elastin that function as structural components of cells and complex organisms, contractile proteins like myosin and actin. Other examples include hormones, allergens, antibodies and storage proteins such as albumin, ferritin and others. ${ }^{9}$

When ingested, the nutritive value of proteins would depend on several factors, for example: protein content, which varies widely among all foods, protein quality, which depends on the amino acids present (essential or nonessential. ${ }^{3}$ Animal sources tend to deliver all the essential amino acids. ${ }^{12}$ Other protein sources, such as fruits, vegetables, grains, nuts and seeds, lack of one or more essential amino acid. These protein sources are considered incomplete proteins. ${ }^{13}$ Other factors that affect the nutritive value are whether the quality complies with human needs and protein digestibility. ${ }^{3}$

According to Aguilar-Miranda \& Nowak et al., ${ }^{2,8}$ when calculating protein content for mealworms, the applied nitrogen-to-protein conversion factor used is 6.25 .

Insects could be preferable to other animal proteins in Readyto-Use Therapeutic Foods (RUTF) applications because less land is required for raising insects compared to typical meat sources. ${ }^{3}$ They can potentially be raised more cheaply. Cost has historically prevented treatments for moderately acute malnutrition (MAM) to include products with milk or other animal proteins from being successful. ${ }^{3}$

The protein content of a variety of insect orders has been determined between 13 and $77 \%$ of dry matter. ${ }^{11}$ Tenebrio Molitor reports values around 13.68 to $22.32 \mathrm{~g} / 100 \mathrm{~g}$ fresh weight. ${ }^{8}$ However, according to Zhao, et al., ${ }^{6}$ half of the dry matter of yellow mealworms was crude 
protein $(\mathrm{CP})(51.4 \%)$. This value is much higher than the one reported by van Huis et al., ${ }^{3}$ as some non-protein nitrogen, including chitin is present in mealworms. Therefore, $\mathrm{CP}$ value over estimated the actual total protein content. Coleoptera larvae were reported by van Huis \& collaborators., ${ }^{1,3}$ to contain between 14 to $25 \mathrm{~g} / 100 \mathrm{~g}$ fresh weight. The discrepancies in protein amounts could be due to differences in methodology, which was not reported for all studies. In general, the protein content of insects is higher than most plants and protein from insect includes around 35 to 50 percent of all the types of essential amino acids. ${ }^{1}$ According to Nowak ${ }^{8}$ protein values in larvae from 13.68 to $25.00 \mathrm{~g} / 100 \mathrm{~g}$ of edible portion (EP). According to van Huis and collaborators (2013), these values are of significance for labeling purposes. Codex Alimentarius (World Health Organization [WHO], ${ }^{14}$ specifies that a food containing $5 \mathrm{~g}$ protein $/ 100 \mathrm{~g}$ can be labeled as "source or protein" and a food containing $10 \mathrm{~g} / 100 \mathrm{~g}$ can be labeled as "high in protein". According to results from Nowalk et al., ${ }^{8}$ all metamorphic stages for T. molitor can be regarded as high in protein. Besides overall content, the amino acids presence determines the protein quality. Tryptophan, lysine and hystidine are the amino acids most commonly mentioned as limiting amino acids of insect protein. ${ }^{11}$ In general, the levels of essential amino acids in insect meals are often compared to and higher than soymeal in FAO food composition tables. ${ }^{11}$

\section{Carbohydrate}

Carbohydrates are widely available in nature, abundant and inexpensive. The elemental composition is carbon atoms along with hydrogen and oxygen. ${ }^{9}$ A great majority of carbohydrate compounds in living organisms are found in the form of oligomers (oligosaccharides) or polymers (polysaccharides) of simple or modified sugars. ${ }^{9}$ Carbohydrates are the least abundant macronutrient found in mealworms. According to Zhao et al., ${ }^{6}$ mealworm larvae contain up to $10 \%$ of other components such as carbohydrates and vitamins. Most of the carbohydrates are thought to come from food remaining in the gastrointestinal tract of the larvae; hence the importance to purge prior processing. ${ }^{1,6}$ When rearing mealworms their diet mainly consists of wheat, wheat bran or oats (for bedding) and carrot, which have a high content of carbohydrates. ${ }^{6}$ According to Durst et al., ${ }^{1}$ the different types of edible insects differ in composition and their carbohydrate contents also vary between 1 and 10 percent. Coleopteran order has an average carbohydrate content of $2.81 \%$ on a dry weight basis. ${ }^{1}$ Insects include the bodies and skin, which are rich in chitin. The content averages between 5 to 15 percent. ${ }^{1}$ Chitin contains nitrogen, is the second most abundant polysaccharide. ${ }^{3}$ It is a naturally occurring polysaccharide of glucosamine, a component of fungal cell walls and the exoskeletons of insects and crustaceans (crabs, lobsters and shrimp). ${ }^{11,15}$ Chitin and the derivative chitosan are produced commercially, by the de-acetylation of chitin., ${ }^{3,11}$ These components have immune modulatory properties that can trigger an allergic reaction, depending on the administration route and the size of the chitin particles. According to van Huis et al., ${ }^{3}$ chitin in medium and large-sized particles are considered to induce allergic inflammation. van Huis et al., ${ }^{3}$ mentioned that chitin is considered indigestible for man and animals and may decrease the insect protein digestibility.

\section{Vitamin and minerals}

Most insects appear to be good sources of trace elements such as iron, zinc, copper, manganese and selenium. ${ }^{1,11}$ T. molitor larvae have notable amounts of calcium, zinc iron and magnesium. ${ }^{8}$
Insects, in general, have been shown to be low in calcium since they do not have an internal skeleton. ${ }^{8}$ In the study by Oonincx et al., ${ }^{7}$ there was a strong correlation between the phosphorus and crude protein content. According to Durst et al., ${ }^{1}$ edible insects are also rich in vitamin $\mathrm{A}$, and vitamins $\mathrm{B}_{1}, \mathrm{~B}_{2}, \mathrm{~B}_{6}, \mathrm{D}, \mathrm{E}, \mathrm{K}$ and $\mathrm{C}$. However, $\mathrm{EFSA}^{11}$ considers information on vitamin content in edible insects to insufficient at present.

According to the definitions for labeling from Codex Alimentarius, ${ }^{14}$ a solid food product is a source of protein, when the protein content is at least $10 \%$ of the Nutrient Reference Value (NRV), and a source of vitamins and minerals, when the content is $15 \%$ of the Nutrient Reference Value. A food product may be labeled as 'high' in a nutrient, when the nutrient value is twice the value required for a 'source'. Table 2 summarizes the values for vitamins and minerals that could be labeled as "source of" or "high in" according to the data found in Nowak et al., ${ }^{8}$ for mineral and vitamin content of larvae of Tenebrio molitor compared to the limits for the label according to Codex. ${ }^{14}$

Table 2 Mineral and vitamin content of Tenebrio molitor in 100g, fresh weight. ${ }^{8}$

\begin{tabular}{llll}
\hline Nutrient & Content & $\begin{array}{l}\text { 'Source of' } \\
\text { according to } \\
\text { WHO' }\end{array}$ & $\begin{array}{l}\text { 'High in' } \\
\text { according to } \\
\text { WHO' }\end{array}$ \\
\hline Iron $(\mathrm{mg})$ & $1.89 \pm 0.93$ & 2.1 & 4.2 \\
Magnesium $(\mathrm{mg})$ & $92.00 \pm 880$ & 45 & 90 \\
Zinc $(\mathrm{mg})$ & $4.33 \pm 0.72$ & 2.25 & 4.5 \\
Riboflavin $(\mathrm{mg})$ & $1.2 \mathrm{I}$ & 0.24 & 0.48 \\
Niacin $(\mathrm{mg})$ & 4.1 & 2.7 & 5.4 \\
Folate $(\mu \mathrm{g})$ & $\mathrm{I})$ & 30 & 60 \\
Vitamin BI2 $(\mu \mathrm{g})$ & 0.3 & 0.15 & 0.3 \\
\hline
\end{tabular}

\section{Food safety quality concerns}

Edible insects are relatively novel ingredients in industrial food processing. It is important to be aware of potential biological, chemical as well as allergenicity and other food safety hazards related with insects reared as food. ${ }^{11}$ The microbial flora of insects is composed of the following bacteria: Staphylococcus, Streptococcus, Bacillus, Proteus, Pseudomonas, Escherichia, Micrococcus, Lactobacillus and Acinetobacte. ${ }^{11}$ EFSA also states that pathogenic bacteria of insects (entomopathogenic) are regarded as harmless to animals and humans due to the fact that the hosts are so phylogenetically different. Any of the bacterial hazards and their derivative toxins that can affect humans and animals related to insects are mainly related and originated from a residential microbiota (natural or accidental) related to the rearing conditions (substrates and feed), handling, processing and preservation.

In this regards, research has shown that insects can pose a significant microbiological threat when used for food purposes and reared in improper conditions. ${ }^{5}$ The main pathogens of concern with mealworms are Enterobacteriaceae and spore-forming bacteria, which are found in the fresh insects at levels standard for food harvested from the soil. Crushed mealworm larvae can have higher counts of viable bacteria, which likely result from the release of intestinal microbiota. ${ }^{16}$ In previous research, Enterobacteriaceae were killed by boiling the insects, but not completely during roasting. Thus, 
lower-temperature roasting may not be sufficient and a blanching step in boiling water may be necessary prior to low-temperature roasting. ${ }^{16}$ Salmonella spp. may be a potential concern, as Salmonella can survive in low water activity products with high lipid content, a category in which mealworm flour might fall into.

The US Food and Drug Administration (FDA) has no special certifications for edible insects, as it requires all food processing facilities to meet the same requirements, and under the European Commission's 2015 Novel Food Regulation, insects fall under the category of "novel food with a history of food use in a third [-world] country [that] has been and continues to be part of the normal diet." Foods in this category require a demonstration of "the history of safe use," which requires documented compositional data and wide experience of use. ${ }^{17}$ However, the lack of specific regulatory guidance has caused issues for investors, farmers and entrepreneurs who are willing to build industrial-scale insect-rearing plants for food and feed. ${ }^{3}$

Another issue of concern is potential allergens. Although any food can potentially be allergenic, arthropods and shellfish very commonly cause allergic reactions due to some non-protein nitrogen, including chitin. ${ }^{17}$ While some people have a history of allergic hypersensitivity, it is also possible to develop serious allergic sensitivity through longterm exposure to an allergen. ${ }^{3}$ A large majority of relevant allergen cases have been due to inhalation or direct and routine contact with the insects. According to van Huis et al., ${ }^{3}$ the likelihood of people having a significant risk of allergenic reaction is small especially for individuals that have no previous history of arthropod allergies or allergen sensitivity. Like other protein-containing foods, arthropods can also induce allergic reactions in sensitive humans. This is a response mediated by immunoglobulin E (IgE). Particle size of chitin seems to play a role. A review of the immunological response to chitin in inducing asthma and allergies revealed that the responses appeared to depend on the particle size of the chitin. Medium-sized chitin particles induce allergic inflammation, while small-sized chitin particles may have the reverse effect of reducing the inflammatory response. $^{3}$

The importance of hygienic handling and correct storage was highlighted by Klunder et al. ${ }^{16}$ study to determine the microbiological content of farmed yellow mealworm larvae (Tenebrio molitor) and house crickets (Acheta domesticus). Boiling the insects in water for a few minutes eliminated Enterobacteriacae. Alternative preservation techniques that do not involve the use of refrigeration are drying and acidification. Lactic fermentation of composite flour/water mixtures containing 10-20percent powdered roasted mealworm larvae showed successful results in acidification which resulted in longer shelf-life and safety by the control of enterobacteria and bacterial spores. ${ }^{16}$

In another study, chemical-physical and microbiological analyses of the following five insect species with rearing potential were carried out, on superworm (Zophobas morio), yellow mealworm (Tenebrio molitor), wax moth (Galleria melonella), butterworm (Chilecomadia moorei) and house cricket (Acheta domesticus). Neither Salmonella nor Listeria monocytogenes were identified in the analyzed samples and it was concluded that it is unlikely that these insects attract microbial flora that pose risks to humans. However, it is still recommended that insects undergo a transformation to render inactive or reduce their microbial content. This could involve cooking (e.g. boiling or roasting) or pasteurization. ${ }^{18}$
Exposure of insects to contamination can be a consequence of the contamination of the substrate used which can contain pathogens and allow their multiplication to an extent, which depends on the characteristics of the substrate itself. ${ }^{11}$ Insects possess the ability to convert low organic material into high quality ingredients. Food waste and manure are common substrates for rearing insects. There is a possible occurrence of microbiological contamination when using protein of animal origin. ${ }^{11}$ It is important to consider the types of organic materials in which insects will be reared.

Prions are proteins that act as infectious pathogens. Unlike other infectious agents, such as bacteria, viruses and fungi, prions do not contain genetic information such as DNA or RNA. Prions contain their genetic information encoded within the conformational structure and posttranslational modifications of the proteins. ${ }^{19}$ The possibility of finding prions in non-processed insects is related to whether or not the substrate source is originated from protein of animal origins. ${ }^{11}$

According to $\mathrm{EFSA}^{11}$ data on the transferring from substrates to insects reared on chemical contaminants is very limited. Yang et al., ${ }^{20}$ reported the presence of polystyrene (PS) degrading bacteria in the guts of mealworms. Gut bacteria found in mealworms were able to depolymerize PS into carbon dioxide, according to the analysis from the worm fecula. When fed with gentamicin (antibiotic) the strain of Exiguobacterium $s p$. strain YT2 was suppressed and mealworms lost the ability to depolymerize. The bacteria found in mealworms created holes and cavities from $(0.2-0.3 \mathrm{~mm}$ in width) (Figure 1).

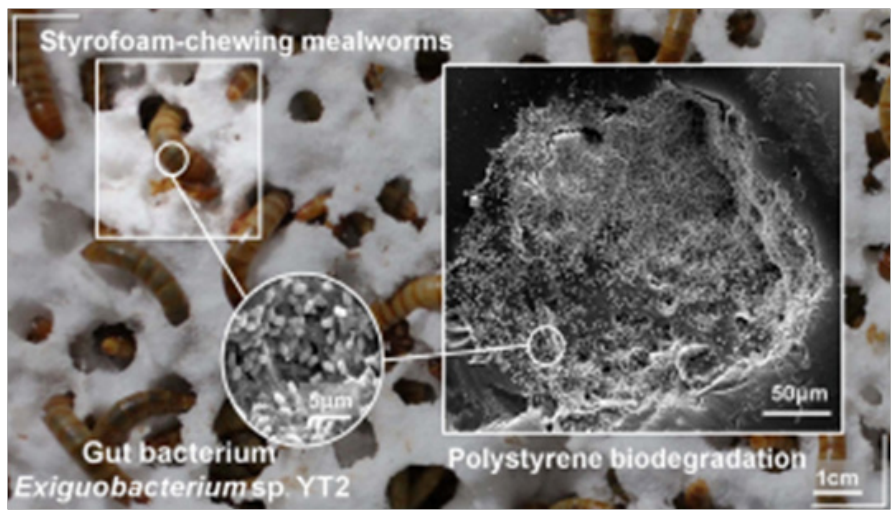

Figure I Gut bacterium Exiguobacterium sp. strain YT2 digesting polysterene. ${ }^{20}$

\section{Role of insects as food and feed in food security}

In contrast to larger domestic food animals where some parts are not economically feasible to use and are almost unusable as food, for example: bones, blood and offal; the entire insect can be used or processed into food. ${ }^{1}$ Insects are a potentially innovative food and feed source, especially with the increasing demands for alternative protein sources worldwide 5 as they are rich in protein (as compared to meat and fish), ${ }^{1}$ fat, minerals and vitamins, Insects are known to have higher feed-conversion efficiency. This means that, insects require less amount of feed for the production of $1 \mathrm{Kg}$ of matter. Insects also have a much higher reproduction and fecundity rates with shorter life cycles. ${ }^{1}$ For example, beetles of $T$. molitor would reach adulthood in a matter of weeks when compared to months taken by an adult bird or years taken by ruminants. ${ }^{17} T$. molitor female beetles would lay an average of 500 eggs. ${ }^{4}$ Moreover, larvae from mealworms 
can be protected from diverse climate conditions: drought, heat and predation with simple techniques such as cloth to cover the containers or to provide shade to their shelters. Edible insects for this reason are unlikely to be affected by abrupt climate changes or environmental calamities. Mealworms, for example, are more drought-resistant than cattle $^{3}$ with the advantage that can be fed on low-value organic waste stream yielding similar nutritional values.

\section{Ready-to-use therapeutic foods (RUTFs)}

There are a number of existing products to treat malnutrition due to food insecurity, including RUTFs, which are usually pastes or drinks that can be directly consumed without further processing; Fortified blended foods, powdered products mostly intended to be cooked as porridge; and other dietary supplements. ${ }^{21}$ The World Food Program (WFP) is a United Nations agency in charge of procurement, logistics and distribution of these fortified blended foods. ${ }^{21}$

The majority of these products, due largely to cost constraints, ease of processing, and nutritional density concerns, have fairly similar ingredients. Most are comprised of low cost vegetable protein or grains, some form of milk powder or whey protein isolate, vegetable oil, micronutrient fortifications, and sometimes sugar. ${ }^{22}$ Examples of these products include nutributter \& plumpy'doz (WFP, nd.). RUTFs result effective for moderate acute malnutrition (MAM) interventions. Isanaka et al., ${ }^{23}$ reports an increase weight for height z-score [WHZ] after a short-term (3month) intervention improving nutritional status, mortality, and morbidity in children. Dairy protein is a nearly ubiquitous ingredient in these products due to the fact that multiple studies have shown that the addition of milk powder as a replacement for cheap vegetable protein like corn or soy increases weight gain in the malnourished children being treated, ${ }^{24}$ and that higher concentrations of milk protein compound this effect. ${ }^{25}$ Higherquality protein (which has a higher concentration of essential amino acids) from milk provides more of the necessary amino acids without increasing satiety by adding more overall protein. Plant products contain higher concentrations of anti-nutrients than milk does. ${ }^{24}$ Thus, while all-vegetable foods for treating MAM are available and cheaper to produce, milk-based products are generally regarded as the best option.

Formulation of these supplemental foods remains a focus of ongoing research, however, as the existing products and programs are far from perfect. There are some technical challenges when addressing RUTFs. For example, finding the nutrients that will be delivered in forms that the human body can absorb (highly bioavailable). Another challenge remains formulating fortified products without unpleasant tastes or odors. This can occur when adding fortificants to food and beverages and designing a stable nutrient delivery systems, preventing changes in a nutrient's chemical composition.

The use of local food products to increase the acceptability of RUTFs as well as reduce costs is gaining popularity as an idea, although the predominantly distributed products are still mainly made of non-local vegetable proteins like soy, corn, and peanut with dairy, another non-local ingredient. ${ }^{22,26}$ Often, the cheapest possible products that meet nutrient guidelines are unfamiliar and unappealing with high amounts of waste stream protein like whey isolate and oil source. ${ }^{27}$ Existing RUTF formulations have had some success increasing acceptability for children with sugar content as high as $28 \%$, but the success does not extend to adults suffering from MAM.
HIV patients and pregnant or nursing mothers ${ }^{28}$ also commonly suffer from malnutrition but are rarely the target audience when RUTFs are being developed because of the focus on child nutrition..$^{21,28}$

Texture is another example of the way that RUTFs are rarely developed with adults in mind. Texture is a concern, which has been studied in the formulation of paste-based RUTFs, but products are optimized for a texture, which can be squeezed out of a package without being thick enough to present a choking hazard to young children. ${ }^{26,29}$

\section{Edible insects for RUTFs}

Edible insects have been traditionally consumed and recently have attracted interest to possibly treat malnutrition and food shortages. Rearing mealworms is part of the concept of mini-livestock with the benefit of not requiring a large amount of land or complicated infrastructure. Moreover, insects are considered as suitable alternatives to conventional animal protein sources comparable to fish, chicken, pork and beef. The farming of mealworms for food can lead to lower emission of greenhouse gases and ammonia when comparing to the emissions from cattle or pigs farming and higher efficiency in converting feed to protein. In a way to secure food, this is a low-tech activity that requires low-capital investment. ${ }^{3}$ From a food safety standpoint and based on the food safety quality considerations, insects can be regarded as safe, if properly managed, reared and consumed. Moreover, in order to reduce any risks associated with safety consumption and achieve a high-quality nutrition product, microbiologically-safe rearing, harvest and post-harvest technologies are required. In order to make the mass production and consumption of insects more attractive as well as more competitive with regard to other animal proteins such as meat or fish, it is necessary to continue researching rearing and harvesting practices, as well as, post-harvest processing technologies including the automation and extract of protein, fatty acids or micronutrient production while ensuring an ingredient that is safe for food and feed consumption.

\section{Acknowledgments}

None.

\section{Conflict of interest}

Author declares no conflict of interest.

\section{References}

1. Durst P, Johnson D, Leslie RN, et al. Forest insects as food: humans bite back. 2010

2. Aguilar-Miranda E. Characteristics of maize flour tortilla supplemented with ground Tenebrio Molitor larvae. J A gric Food Chem. 2002;50(1):192_ 195.

3. van Huis A, Van Itterbeeck J, Klunder H, et al. Edible insects Future prospects for food and feed security. FAO Forestry. Rome: Food and Agriculture Organization; 2013.

4. Alves AV, Sanjinez-Argandona E, Linzmeier A, et al. Food value of mealworm grown on Acrocomia aculeata pulp flour. PLoS One. 2016;11(3):1-11.

5. Rumpold B, Schlüter O. Potential and challenges of insects as an innovative source for food and feed production. Innovative Food Science and Emerging Technologies. 2013;17:1-11. 
6. Zhao X, Vázquez-gutiérrez JL, Johansson DP, et al. Yellow mealworm protein for food purposes - extraction and functional properties. PLoS ONE. 2016;11(2):1-18

7. Oonincx DGAB, Van Broekhoven S, van Huis A, et al. Feed conversion, survival and development, and composition of four insect species on diets composed of food by-products. PLOS ONE. 2015;10(12):1-20

8. Nowak V, Persijn D, Rittenschober D, et al. Review of food composition data for edible insects. Food Chemistry. 2016;193:39-46.

9. Fennema O. Food Chemistry. 3rd ed. Marcel Dekker, New York, USA 1996.

10. Byrd-Bredbenner C. Wardlaw's Perspectives in Nutrition. 9th ed. New York, McGraw-Hill; 2009.

11. European Food Safety Authority. Risk profile related to production and consumption of insects as food and feed EFSA Scientific Committee. EJ EFSA Journal. 2015;13(10):1-60.

12. The National Academics of Science, Engineering, Medicine. Dietary Reference Intakes for Energy, Carbohydrate, Fiber, Fat, Fatty Acids, Cholesterol, Protein, and Amino Acids. 2015).

13. United States Department of Agriculture. Food composition tables. 2016

14. World Health Organization and Food and Agriculture Organization of the United Nations. Codex Alimentarius. Food Labeling 5th ed. Rome: Food and Agriculture Organization; 2007.

15. Whitford D. Proteins, Structure and Function. New York, Wiley and Sons; 2005.

16. Klunder H, Wolkers-Rooijackers J, Korpela J, et al. Microbiological aspects of processing and storage of edible insects. Food Control. 2012;26(2):628-631.

17. Belluco S, Losasso C, Maggioletti M, et al. Edible insects in a food safety and nutritional perspective: A critical review. Comprehensive Reviews in Food Science and Food Safety. 2013;12(3):296-313.

18. Giaccone V. Hygiene and health features of "minilivestock". In: MG Paoletti editor. Ecological implications of minilivestock; role of rodents, frogs, snails, and insects for sustainable development. New Hampshire: Science Publishers; 2005.
19. Das AS, Zou W. Prions: Beyond a single protein. Clin Microbiol Rev. 2016;29(3):633-658

20. Yang Y, Yang J, Wu W, et al. Biodegradation and Mineralization of Polystyrene by Plastic-Eating Mealworms: Part 2. Role of Gut Microorganisms. Environ Sci Technol. 2015;49(20):12087-12093.

21. World Food Program.

22. Annan RA, Webb P, Brown R. Management of moderate acute malnutrition (MAM): current knowledge and practice. In CMAM Forum Technical Brief. 2014;1-39.

23. Isanaka S, Nombela N, Djibo A, et al. Effect of preventive supplementation with ready-to-use therapeutic food on the nutritional status, mortality, and morbidity of children aged 6 to 60 months in niger: A cluster randomized trial. JAMA. 2009;301(3):277-285.

24. Hoppe C, Andersen G, Jacobsen S, et al. The use of whey or skimmed milk powder in fortified blended foods for vulnerable groups. $J$ Nutr. 2008;(138):145-161.

25. Oakley E, Reinking J, Sandige H, et al. A ready-to-use therapeutic food containing $10 \%$ milk is less effective than one with $25 \%$ milk in the treatment of severely malnourished children. J Nutr. 2010;140(12):22482252 .

26. Bechman A, Phillips R, Chen J. The use of nutrient-optimizing/costminimizing software to develop ready-to-use therapeutic foods for malnourished pregnant women in Mali. Food Sci Nutr. 2015;3(2):110 119.

27. Weber J, Callaghan M. Optimizing ready-to-use therapeutic Foods for protein quality, cost, and acceptability. Food Nutr Bull. 2016;37(1):3746.

28. Dibari F, Diop EHI, Collins S, et al. Low-cost, ready-to-use therapeutic foods can be designed using locally available commodities with the aid of linear programming. J Nutr. 2012;142(5):955-961.

29. Oonincx DGAB, de Boer IJM. Environmental impact of the production of mealworms as a protein source for humans - A life cycle assessment. PLOS ONE. 2012;7(12):1-6. 